\title{
Collaborative Learning using tablets in EFL to develop Oral Communication
}

\author{
Sílvia Roda Couvaneiro \\ Institute of Education- University of Lisbon \\ Alameda da Universidade \\ 1649-013 Lisboa \\ +351217943633 \\ silvia.couvaneiro@campus.ul.pt
}

\author{
Neuza Pedro \\ Institute of Education- University of Lisbon \\ Alameda da Universidade \\ 1649-013 Lisboa \\ +351217943690 \\ nspedro@ie.ulisboa.pt
}

\begin{abstract}
This paper describes a study with two Portuguese 8th grade classes and two teachers about Teaching English as a Foreign Language (TEFL) and the use of tablets, which implied implementing a didactic unit using several iPad devices. For that, an iBook and other digital educational resources were produced for students to explore together in class and to test their reading comprehension in small groups. Each group also had to produce a short video that was to be presented to class afterwards. The main goal was to evaluate the impact of this unit on: i) oral communication development, ii) student motivation, and iii) teachers' adoption of tablets. Students and teachers were surveyed before and after the deployment. The students' products were also evaluated, to assess oral production skills, and the teachers were interviewed at the end of the study. This mixed methodology of data collection and analysis proved the existence of a positive impact of the project concerning the three constructs under analysis.
\end{abstract}

\section{Categories and Subject Descriptors}

Applied Computing - Education - Collaborative Learning

\section{General Terms}

Experimentation, Languages

\section{Keywords}

TEFL (Teaching English as a Foreign Language), collaborative learning, iPad, tablets, oral communication

Permission to make digital or hard copies of all or part of this work for personal or classroom use is granted without fee provided that copies are not made or distributed for profit or commercial advantage and that copies bear this notice and the full citation on the first page. Copyrights for components of this work owned by others than the author(s) must be honored. Abstracting with credit is permitted. To copy otherwise, or republish, to post on servers or to redistribute to lists, requires prior specific permission and/or a fee. Request permissions from Permissions@acm.org.

TEEM '15, October 07 - 09, 2015, Porto, Portugal

Copyright is held by the owner/author(s). Publication rights licensed to ACM. ACM 978-1-4503-3442-6/15/10 ..\$15.00

DOI: http://dx.doi.org/10.1145/2808580.2808602

\section{INTEGRATING MOBILE TECHNOLOGIES}

The pedagogical integration of mobile technologies, and more recently of tablets, has been widely studied, mostly motivated by what the technological development has allowed to concentrate on a single device. Tablets now gather several elements that before would require many different devices and time-consuming processes. Entities such as the European Commission or the UNESCO have already acknowledged these devices' advantages for education, not only because they allow access to information and equity in the teaching-learning processes $[1 ; 2]$, but also for price issues, portability and ubiquity when compared to laptops or personal computers, connectivity, and adaptability, since these may even allow individual as well as collaborative learning.

For this study several studies and reports, regarding the educational integration of the tablet iPad, were analysed. These revealed that this device has been used in different educational contexts, being its potential largely described and appreciated when it comes to formal education at schools, universities, laboratories, libraries, as well as special needs contexts $[3 ; 4 ; 5 ; 6]$.

This tablet's characteristics are considered appropriate and advantageous for education, being these what seems to justify the educational potential signalled by the literature. According to Crichton, Pegler and White (2012) the advantages are not only the easy internet and other resources access, such as applications (apps), but also the long-life battery, size and usability [7]. Hutchinson, Beschorner and Schmidt-Crawford considered the apps can potentially transform the device, as they might allow access to different resources and sources of information, simulations, communication situations and production processes that would be impossible otherwise [8].

Having the same dimensions of a book, portability is one of the characteristics pointed out for education $[3 ; 8 ; 9]$, as it allows students to move around the classroom easily, but also outside it, beyond the classrooms', or even the school's walls. Such characteristics might bring students' projects to reach wider spaces and possibly audiences [10]. The multitouch screen is also pointed out as a positive feature for education [5; 9], as researchers consider it may allow a more intuitive usage by very young learners than with a mouse and a desktop $[11 ; 12]$. Using one single device that gathers different elements seems to transform classroom processes 
and dynamics, referring authors an added playfulness to learning [13] and a sense of self-confidence and autonomy [14].

As for the national research regarding specifically the iPad tablet, there were only but a few studies for the same period of time that was researched (2011-2014). Nevertheless, they all point out the same potential for different educational contexts, having studied it for the e-Inclusion of seniores [15], communication and interaction in special education [16], as well as for the use of apps for multiple disabilities [17]. The software iBooks Author for Mac has been elected as the best to produce ebooks for the tablet iPad [18] as it allows the integration of several interactive elements within an iBook, such as sound, interactive pictures, video, glossary, underline and speech features, or exercises with immediate feedback.

The papers analysed seem to concur on this tablet's educational potential, agreeing that it might bring other possibilities to learning [8], namely due to this technology's adaptability to each student's needs and interests, and therefore for promoting learning differentiation $[12 ; 14 ; 19]$. Student motivation and involvement in classroom activities are also signalled as aspects with a relevant difference $[19 ; 20 ; 21 ; 22]$. The possibility of allowing students a choice on their learning paths $[8 ; 21]$ became more relevant when this technology was used with children with multiple disabilities [23]. Motivation appears associated to an increased creativity in the teaching-learning process $[8 ; 14]$, being the variety and quality of productions, both students' and teachers', underlined as another relevant improvement [19].

Collaborative learning is another advantage authors have pointed out. Hutchison et al. consider it to be potentially transformed due to different dynamics in class with children [8]. Ensor refers that in groups students can share their learning and findings, also gaining independence as learners, instead of focusing solely on the teacher's considerations and explanations [14]. Also Aronin and Floyd as well as Karsenti and Fievez signalled gains in terms of how easy it is to organise youngsters to work collaboratively in class $[13 ; 19]$. Eichenlaub et al. proved the same in terms of higher education students [9]. Collaborative work among teachers taking part of such deployment projects was also noticed as teachers can share issues beyond the curricula, considering their fluency while working with the iPad in class, as well as in the development of ICT skills $[14 ; 19]$. That sharing behaviour also happened between very young children [8].

In the context of Teaching English as a Foreign Language (TEFL) the work of Huber was analysed. The author focused on the iPad deployment in the context of the Austrian TEFL reality. Several apps were tested and evaluated according to the Austrian curriculum for TEFL, which objectives, tasks and concepts coincide with the Portuguese. The study turned out to prove that almost the entire set of objectives can be promoted with the help of this device. In particular when focusing the communicative competence as a whole and its variants evenly; the social and intercultural competence; the acquisition of learning strategies; and the support of teaching concepts. While trying to prove a successful integration model of this technology in TEFL, this author concluded that an active and interactive participation will lead to a more meaningful learning of the English language, and particularly emphasised the appropriateness of using the iPad and in combination with different apps [4].

Some disadvantages were also pointed out on this integration. Huber stated that the written production and correction may be slower [4], being a disadvantage also marked by Karsenti and
Fievez [19]. Crichton et al. indicated the need for a good management of device user accounts [7], as this device is designed for individual use. Gentile reported a solution by using a mobile device management (MDM) system [24]. These authors agreed that there might be a risk of greater distraction in the classroom, having Karsenti and Fievez reported that both teachers and students agree on that, requiring the establishment of specific rules of use in class or monitoring the use of these equipments with MDM.

Several studies also reported the urgent need for constant technical support as well as for teacher training, regarding both the teachers' technological fluency and the devices' proper curriculum integration $[4 ; 6 ; 18 ; 19 ; 22]$. Peluso defends it is unreasonable not to include the technological advances in schools, and that misconceptions about this technology's tendency to lead students to fun and games should be cleared. The author considers it an essential tool in class and a source of motivation for learning that requires appropriate pedagogical reflection, as students should also be given a chance to critically reflect and decide upon their use of technology and how it can help them learn better [22].

In short, it seems evident that the iPad can add value to learning contexts, being preferred based on its characteristics and high level of usability. The most significant aspects about the educational use of the iPad reported by the literature review concern the approach to the needs and interests of students as a form of motivation; the possibility of differentiation; the development of a large range of skills, including those related to the use of technologies; the possibility of individual work as well as an autonomous collaborative work; independence from teacher exposure; and creative production of different artefacts. These and other aspects turned out to be a starting point for the research questions of the present study, as well as to discuss the results of its implementation.

\section{METHODOLOGY AND INSTRUMENTS}

This study was conducted during the school year 2013/2014, having had several stages before the implementation of a teaching unit (unit): i) a systematic literature review, ii) the preparation of the data collection instruments, and iii) the planning of a unit with the production of the required digital educational resources (DER).

The literature review allowed to deepen the interest on mobile technologies and their pedagogical integration and understand how this relation has been studied. The research was planned, following the adequate procedures to carry out a systematic literature review [25] in order to gather and systematise evidence from several studies in this field. These were then organised in a table, summarising the studies' characteristics, allowing an easier review of the studies' results and conclusions [26].

The literature review focused on the following criteria: a) scientific studies in formal educational settings that analysed the impact of iPad integration in learning; b) studies on TEFL that made use of mobile technologies; c) studies conducted by Apple in formal learning contexts. Thus 22 scientific papers were analysed according to the criteria a); 2 studies in accordance to criteria $b$ ); and, regarding criteria c), 2 Apple Classrooms of Tomorrow reports. Additionally, two relevant reports were also considered due to the significant number of participants (about 6,000 students).

The topic of mobile technologies integration was regarded as an innovative practice that could have positive effects on learning. Thus, this study tried to corroborate the potential referred in the literature, exploring the device's characteristics and apps to verify 
the impact on motivation and on the learning of English as a Foreign Language. According to the advantages raised in the literature, the unit planned considered providing creative opportunities for interaction and collaboration. These could lead to a difference in student motivation, and thus to the development of the communicative competence, more specifically of oral production in English. Three research questions were formulated accordingly, looking for a possible impact on i) students' motivation towards learning the English language; ii) the development of the communicative competence, specifically oral production; and iii) the teachers' use of these technologies in their teaching practices.

The unit was then planned to implement an 'Extensive Reading' activity that could easily be developed at any period of the school year in both schools. It considered students would explore an iBook collaboratively, using one iPad per group, reading and solving exercises together, and having to produce a video afterwards on the same topic. The main objective was to improve students' oral production. This unit was implemented with two English teachers and with their two 8th grade classes, in two private schools of Lisbon' educational area.

Students started their work on this unit by entering a virtual classroom, created using the Edmodo website. This space was used throughout the unit for students to share various elements and productions and to write comments about other students' productions, having allowed the spontaneous participation about the work being done. The initial resources and access to iTunesU were shared in Edmodo. Afterwards students accessed iTunesU where they could download all the DER and consult their tasks, that were thoroughly described. This allowed the groups to start working collaboratively and autonomously, while the teachers would move around the classroom and help when necessary. The students could consult each task, having with it all the resources necessary, and could use a checklist to confirm the ones that were being concluded. There was also a final script available that the pupils could follow with detailed instructions on what to do, which apps could be used and how, and a model video that should be taken into account as an example for the groups' final productions.

One of the central DER in the unit was an iBook created specifically for this study, using the iBooks Author for Mac software. This iBook integrated text, pictures with information, videos and interactive exercises with immediate feedback. In their groups, students explored information about the author that was being study Isaac Asimov, as well as his three laws of robotics, and a short story - "Someday". They were also able to use the interactive glossary, organised with text and pictures, and according to the words that would be difficult for the students' level of English. Students also used the speech feature when they wanted it to take turns in reading, or did not know how to pronounce a word. They worked in groups, reading the story aloud collaboratively, with all the elements in the group being responsible for the understanding of the whole story - thus, everyone was involved. While reading, the group was required to sketch, using pencil and paper, one of the elements described in the story, for which they had no visuals, having the whole group to agree on what it looked like. These sketches were photographed and shared in the groups' virtual classroom at the end of the reading activity, having students written comments on that, discussing it orally on the subsequent lesson.

Following the theme of the story, and the predictions that Asimov did in 1964 about 2014 technology available in the iBook, students followed a script to produce an animation using pictures collected online with the ExplainEverything application. Then they included it on their own '2064 news report' using a CNN template of the iMovie app.

They predicted a future form of technology and created its first appearance in public in the form of a news report, always using the English language, even if in a prepared way, as expected for this level of education, A2 - 8th grade [27]. The groups followed the directions of the teachers and the steps in the script to produce a video, similar to the example provided. The productions were shared with the class in Edmodo and in the classroom. Having each group presenting their news report provided good moments of debate among students, including on the use of technology.

The research design included various data collection moments, which happened according to the unit. The methodology followed the assumptions of the pragmatic paradigm [28; 29], placing the research problem at the center of all procedures. The study followed a mixed methodology of data collection and analysis, hence both quantitative and qualitative data were considered imperative, given the specificity of the research questions and their diversity.

The multi-methodological research plan for collecting and analysing data [30] allowed focusing on all the goals that guided the study. The data collection moments were outlined to develop a sequential explanatory strategy. The collection and analysis moments of the quantitative data were followed by the collection and analysis of the qualitative data [28].

Both students and teachers were surveyed before and after the unit. The students' productions were also collected at the end of the unit. After a preliminary analysis of these data, the teachers' interview was prepared accordingly to collect more data that could contribute to all the research questions. Thus, both teachers were interviewed after the whole process, which allowed to scrutinise the explanation and interpretation of the initial results. Each quantitative data collection instrument was driven by a research question. On the other hand the qualitative data looked to bring contributions to all of them.

For the students' questionnaire the instrument elected was "The Attitude / Motivation Test Battery" (AMTB) by Gardner [31; 32] to measure the students' motivation (27 students in school 1 and 26 students in school 2) towards the learning of the foreign language, before and after the implementation of the unit. This aimed to contribute to answering the first research question.

For the second research question, an instrument to assess the students' products was designed. In total 13 video projects from the two schools were analysed. To quantify this assessment, and to make it more objective, a 5-points scale was established with the respective descriptors for the three parameters: originality, quality and use of the English language. For the latter, the following were taken into account: i) the adequacy of the product within the activity objectives; ii) the curriculum goals regarding Spoken Production of English [27]; and iii) the language proficiency level A2, according to the Common European Framework of Reference for Languages [33].

As for the questionnaire applied to the teachers before and after the unit, which aimed to respond to the third research question, it was designed based on the Portuguese translation and validation of the "Teacher's Technology Use Scale" (TTUS) of Bebell, Russell and O'Dwyer [34].

The interview was the last data collection instrument used to confirm and deepen all the previous data and the preliminary 
findings previously measured. This interview was organised in a semi-structured manner, with open questions directed specifically to the research questions and naming the preliminary data obtained with the other instruments. The teachers' perceptions regarding the students' motivation and products, as well as how the technologies were integrated into the unit, their practices and work in class, were considered valuable contributions that would help understand an eventual impact on the three aspects.

\section{RESULTS AND CONSIDERATIONS}

The results obtained with all the data collected triggered a reflection on each of the research questions. These results seem to be favourable, indicating a positive impact of the project.

As for the first research question, which considered student motivation towards learning the English language, no significant changes were found according to the questionnaires applied to the students. The measurement of motivation revealed that both groups of students already had high levels of motivation prior to the unit implementation (school 1 - 87.99 and school 2 - 91.97, in a maximum of 110 points) and these values also remained high afterwards (87.66 and 93.58 respectively). However, the teachers' perceptions pointed otherwise, having both felt that there were differences in student motivation during the unit implementation. Both teachers indicated an increase in student involvement, high motivation for learning and particularly in terms of use of the English language. They also noted a more disciplined attitude and a more positive and active participation of students. Another interesting aspect related to motivation was the fact that, in the questionnaire, students showed preference for music related learning, television and theatre, which could point to a positive identification with the strategies adopted and the creative nature of the project, which implied the creation of a news video with a futuristic projection.

The second research question focused on the development of the communicative competence, particularly the oral production in English. The evaluation of the students' productions revealed a high global average in the use of English (school 1 mean $=4.7$ and school 2 mean $=4.4$, in a maximum of 5 points). Teachers referred the fact that both classes were already generally good but noted a more spontaneous oral participation of students in class. Teachers referred that it tend to happen more often and also underlined the particular case of the students who usually struggle to do so, being these students the ones the teachers felt revealed a more positive difference.

Finally, the third research question concerned the perception of how teachers made pedagogical use of these technologies and in which dimensions of their practice there were differences to register. The questionnaires applied to the teachers revealed that the tendency of the educational use of technology in their usual practice and within this unit was indeed quite different. Not only did they consider that they used technologies more often, but they also used them for more diversified purposes, focusing now primarily on tasks performed in class and supporting students' productions. In their interviews both teachers revealed that they recognised a transformative potential to the mobile devices used in this study, since they found these moments of work with the students to be very different from their usual practices, referring favourable differences on motivation, involvement and student achievement, particularly in what oral production is concerned.
One of the limitations of this study concerns students struggling to learn English. The impact on the students with different types of difficulties and needs was surprisingly highlighted by teachers, being in these cases that both teachers identified more relevant differences. For this study, it would have been appropriate to identify these students and those with special needs, analysing their situations individually, since it could also corroborate the advantages of differentiation signalled by the literature.

There are some relevant issues that should not be overlooked in future studies - differentiation and respecting students' individual interests should be considered. These were not, however, object of analysis in the present study. It would have been an important step to explore the possibility of students deciding which artefacts would be the most appropriate to produce according to the learning situations and goals, as noted by Peluso [22]. Similarly, it would have been more productive to carry out a study for a longer period of time, rather than implementing a single teaching unit. This was also pointed out by the teachers in their interviews, having both considered that, had students had more time to get used to the devices, they would be more fluent in their use. Also, using one tablet per student might also allow individualising each student's progression in the course of a school year. The long-term might also allow the individual assessment of the communicative competence by each of the students and in its various aspects: comprehension, interaction and production, both oral and written.

The early and timely training of the participating teachers, focusing both on their technological fluency and on the pedagogical integration of such technologies seems to be fundamental for such implementations to be successful. The differences between the two teachers in terms of their prior knowledge was eventually felt. The teacher in school 2, who already owned an iPad and had mastered its use, even using it in class, took full advantage of the project for her professional development, having explored new apps, using the DER in more depth and with other classes as well. It would have been appropriate to devote more time to the prior initial training and to allow that both could have explored this technology out of school. Had this study done so, it could have been a more profitable opportunity for both of them to develop their teaching and ICT skills.

Regarding the disadvantage highlighted by the literature that concerned the possible focus of distraction added to the classroom $[4 ; 19]$, it is safe to say it was not an issue in this study, as it was not made evident throughout the whole implementation. Contrarily, the teacher in school 2 actually stressed precisely the opposite in her group of students: "The biggest difference to be registered was the degree of student involvement (...) all participated [and] developed their projects orderly, in silence and in collaboration." It should be noted that the initial moments of contact with the students, still before working with the devices, involved establishing rules to be followed in class.

These favourable results, even though they can not be generalised, can hopefully motivate other similar classroom experiences and give rise to other reflections on pedagogical integration of mobile technologies in the classroom to support students' learning. Furthermore, this study might contribute to the awareness of the need to innovate with ICT in Education, more specifically taking advantage of new mobile technologies. 


\section{REFERENCES}

[1] Digital Agenda for Europe, 2012. European Commission. Available at http://ec.europa.eu/digital-agenda/.

[2] UNESCO, 2013. Policy Guidelines for Mobile Learning. Available at http://unesdoc.unesco.org/images/0021/002196/219641e.pdf.

[3] Gawelek, M.A., Spataro, M. and Komarny, P., 2011. Mobile perspectives: On iPads - Why mobile? EDUCAUSE Review, 46(2), 28-32.

[4] Huber, S., 2012. iPads in the classroom - A development of a taxonomy for the use of tablets in schools. Doctoral Thesis in Information Systems and Computer Media. Graz: University of Technology.

[5] Kagohara, D.M., Meer, L., Ramdoss, S., O’Reilly, M., Lancioni, G., Davis, T., Rispoli, M., Lang, R., Marschik, P., Sutherland, D., Green, V. and Sigafoos, J., 2013. Using iPods and iPads in teaching programs for individuals with developmental disabilities: A systemic review. Research in Developmental Disabilities, 34(1),147-156.

[6] O’Malley, P., Jenkins, S., Wesley, B., Donehower, C. and Rabuck, D., 2013. Effectiveness of using iPads to build math fluency. In Council for Exceptional Children Annual Meeting. San Antonio, Texas.

[7] Crichton, S., Pegler, K., and White, D., 2012. Personal devices in public settings: Lessons learned from an iPod touch / iPad project. The Electronic Journal of e-Learning, 10(1), 23-31.

[8] Hutchison, A., Beschorner, B. and Schmidt-Crawford, D., 2012. Exploring the use of the iPad for Literacy Learning. International Reading Association - The Reading Teacher, $66(1), 15-23$

[9] Eichenlaub, N., Gabel, L., Jakubek, D., McCarthy, G. and Wang, W., 2011. Project iPad: Investigating tablet integration in learning and libraries at Ryerson University. Computers in Libraries, 31(7), 17-21.

[10] Clark, W. and Luckin, R., 2013. What the research says iPads in the Classroom. London Knowledge Lab, Institute of Education-University of London.

[11] Beschorner, B. and Hutchison, A., 2013. iPads as a literacy teaching tool in early childhood. International Journal of Education in Mathematics, Science and Technology, 1(1), 1624.

[12] Shah, N., 2011. Special education students find learning tool in iPad applications. Education Week, 30(22), and16-17.

[13] Aronin, S. and Floyd, K., 2013. Using an iPad in inclusive preschool classrooms to Introduce STEM Concepts. Teaching Exceptional Children, 45(4), 34-39.

[14] Ensor, T., 2012. Teaming with technology: "Real" iPad applications. Journal of Adolescent \& Adult Literacy, 56(3), 193.

[15] Fonseca, I. 2011. O uso de dispositivos multitácteis para a infoinclusão do sénior. Master Thesis on Multimidia Communication, Department of Communication and ArtsUniversity of Aveiro.

[16] Ramos, A., Ferreira, S. and Reis, S., 2012. Análise das potencialidades do iPad visualizadas nos vídeos do YouTube no âmbito das necessidades educativas especiais. Internet latent corpus Journal, 2(2), 5-18.
[17] Feijão, M. H., 2013. A multideficiência e as tecnologias de informação e comunicação. Master Thesis in ICT in Education, Institute of Education - University of Lisbon.

[18] Bidarra, J., Figueiredo, M., Valadas, S. and Vilhena, C., 2012. O gamebook como modelo pedagógico: Investigação e desenvolvimento de um protótipo para iPad. In A. A. A. Carvalho (Org.), Aprender na era digital: Jogos e MobileLearning (pp. 83-109). Santo Tirso, DeFacto Editores.

[19] Karsenti, T. and Fievez, A., 2013. The iPad in education: uses, benefits, and challenges - A survey of 6,057 students and 302 teachers in Quebec, Canada. Montreal, QC: CRIFPE.

[20] Carr, J. M., 2012. Does math achievement happen when iPads and game-based learning are incorporated into fifth-grade mathematics instruction? Journal of Information Technology Education: Research, 11, 269-286.

[21] Hesser, T. and Schwartz, P., 2013. iPads in the Science laboratory: Experience in designing and implementing a paperless chemistry laboratory course. Journal of STEM Education 14(2), 5-9.

[22] Peluso, D., 2012. The fast-paced iPad revolution: Can educators stay up to date and relevant about these ubiquitous devices? British Journal of Educational Technology, 43(4), 125- 127.

[23] Helps, H. and Herzberg, T., 2013. Practice report: the use of an iPad2 as a leisure activity for a student with multiple disabilities. Journal of Visual Impairment and Blindness, 107(3), 232-236.

[24] Gentile, M., 2012. The importance of managing iPads in the classroom. Education Digest, 78(3), 11.

[25] Gough, D., Oliver, S. and Thomas, J., 2012. An introduction to systematic reviews. London, SAGE Publications Ltd.

[26] Vilelas, J., 2009. Investigação: O processo de construção de conhecimento. Lisbon: Edições Sílabo.

[27] Cravo, A., Bravo, C. and Duarte, E., 2013. Metas Curriculares de Inglês - Ensino Básico: $2^{\circ}$ e $3^{\circ}$ Ciclos. Lisbon: Ministry of Education and Science.

[28] Creswell, J. W., 2003. Research design qualitative quantitative and mixed methods (4th Edition). Washington, DC, SAGE Publications.

[29] Mertens, D., 2014. Research and evaluation in Education and Psychology - Integrating diversity with quantitative, qualitative, and mixed methods (4th Edition). Washington, DC, SAGE Publications.

[30] Robson, C., 2011. Real World Research. UK: WileyBlackwell.

[31] Gardner, R. C., 1985. Motivation/Attitude Test Battery Manual. Available at http:// publish.uwo.ca/ gardner/.

[32] Gardner, R. C. 2004. Attitude/Motivation Test Battery: International AMTB Research Project (English version). Available at http://publish.uwo.ca/ gardner/.

[33] Conselho da Europa, 2001. Quadro europeu comum de referência para as línguas. Aprendizagem, ensino e avaliação. Lisboa: Edições Asa.

[34] Pedro, N. 2012. 'Integração Educativa das TIC': uma nova abordagem ao conceito. Educação Formação e Tecnologias, 5(1), 3-16. Available at http://eft.educom.pt/index.php/eft/article/view/253. 